\title{
Asymmetric synthesis of biaryl atropisomers by dynamic resolution on condensation of biaryl aldehydes with (-)-ephedrine or a proline-derived diamine
}

Ann Bracegirdle, Jonathan Clayden* and Lai Wah Lai

\section{Full Research Paper}

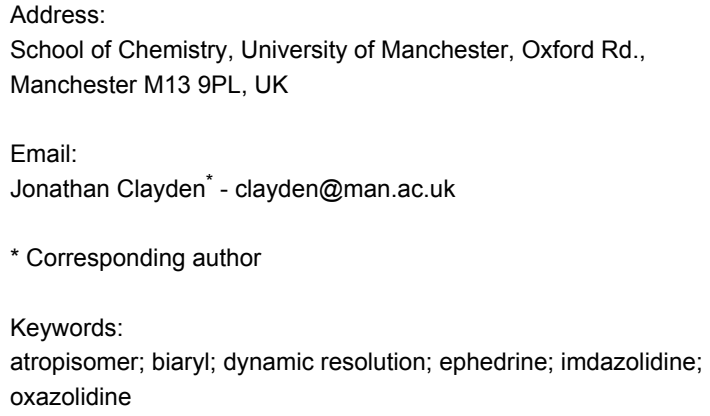

\author{
Beilstein Journal of Organic Chemistry 2008, 4, No. 47. \\ doi:10.3762/bjoc. 4.47 \\ Received: 27 August 2008 \\ Accepted: 20 November 2008 \\ Published: 04 December 2008 \\ (C) 2008 Bracegirdle et al; licensee Beilstein-Institut. \\ License and terms: see end of document.
}

\begin{abstract}
Atropisomeric biaryl aldehydes undergo diastereoselective condensation with (-)-ephedrine and with a proline-derived diamine, with selectivity highly dependent on solvent, temperature and reaction conditions. Levels of thermodynamic control up to 5:1 may be obtained by heating the diamine with the aldehyde in a sealed tube. Alternatively, crystallisation-induced dynamic transformation allows isolation of a single diastereoisomer in up to $85 \%$ yield. Hydrolysis and reduction of the major diastereoisomeric product of the reaction yields atropisomeric biaryls in $>99: 1$ enantiomeric ratios.
\end{abstract}

\section{Introduction}

Atropisomeric biaryl compounds have proved to be among the most successful of all chiral ligands for metal-catalysed asymmetric transformations [1,2]. Many biaryl ligands have been obtained in enantiomerically pure form by means of resolution [3], but there are also a number of important enantioselective methods for the synthesis of biaryls [4-9].

In view of the thermal instability inherent in a stereogenic bond (rather than a centre) dynamic methods appear particularly suited to the stereoselective synthesis of atropisomers [10,11]. In connection with our work on non-biaryl atropisomers such as amides [12-16], ethers [17] and ureas [18-20], we have explored the opportunities offered by dynamic kinetic [21-23] and dynamic thermodynamic [24] resolution [11,16,25-30]. We reported methods for the latter based on resolving "auxiliaries" which include silylethyl groups [28], proline-derived imidazolidines [25,27], ephedrine-derived oxazolidines [26,27], and, most extensively, sulfoxides [16,29-31]. These perform well when a powerful electronic or steric bias is evident about the atropisomeric bond over which control is applied [32], and in the case of atropisomeric amides have offered levels of conformational control up to 200:1 [33]. 
In this paper we present our extension of this work to the more conventional family of biphenyl compounds, which present a more challenging group of substrates because of the lack of steric or electronic contrast between the two conformers about an $\mathrm{Ar}-\mathrm{Ar}$ bond. We find that a thermodynamic resolution is possible in certain cases and under rather precisely defined conditions. We propose a rationale for the selectivities observed which invoke thermodynamic resolution enabled by the presence of water.

\section{Results and Discussion}

\section{Synthesis of the racemic substrates}

Previous success with stereocontrol employing ephedrinederived oxazolidines $[15,26,27,34,35]$ and proline-derived imidazolidines $[25,27]$ prompted us to investigate the thermal stability and conformational preferences of similar products arising from condensation reactions of 2-formylbiaryls. A family of starting aldehydes $\mathbf{6 a}-\mathbf{f}$ was made by the method of Meyers [36]. 2,3-Dimethoxybenzoic acid (1) was converted via its acyl chloride to oxazoline $\mathbf{3}$, from which the 2-methoxy
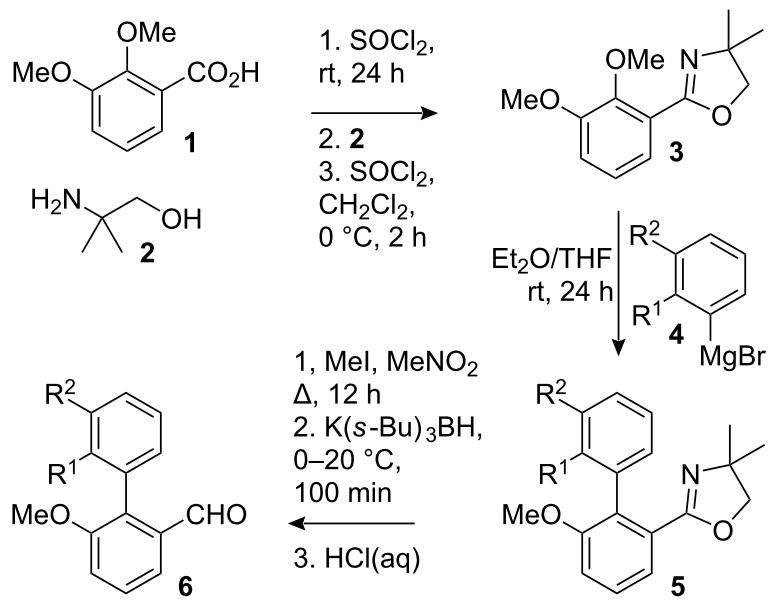

1, $\mathrm{Mel}, \mathrm{MeNO}_{2}$
$\triangle, 12 \mathrm{~h}$
2. $\mathrm{K}(\mathrm{s}-\mathrm{Bu})_{3} \mathrm{BH}$,

$0-20^{\circ} \mathrm{C}$, $100 \mathrm{~min}$

3. $\mathrm{HCl}(\mathrm{aq})$

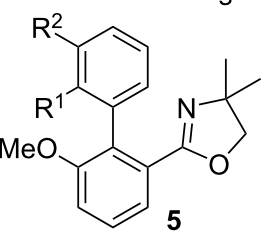

Scheme 1: Synthesis of racemic aldehydes.

Table 1: Synthesis of biaryl aldehydes 6.

\begin{tabular}{llll} 
entry & $\mathrm{R}^{1}, \mathrm{R}^{2}$ & $\begin{array}{l}\text { Oxazoline } \mathbf{5}, \\
\text { yield }\end{array}$ & $\begin{array}{l}\text { Aldehyde } \mathbf{6}, \\
\text { yield }\end{array}$ \\
\hline 1 & $\mathrm{MeO}, \mathrm{H}$ & $\mathbf{5 a}, 82$ & $\mathbf{6 a}, 70$ \\
2 & $\mathrm{EtO}, \mathrm{H}$ & $\mathbf{5 b}, 84$ & $\mathbf{6 b}, 71$ \\
3 & $i-\mathrm{PrO}, \mathrm{H}$ & $\mathbf{5 c}, 79$ & $\mathbf{6 c}, 45$ \\
4 & $\mathrm{Me}, \mathrm{H}$ & $\mathbf{5 d}, 80$ & $\mathbf{6 d}, 71$ \\
5 & Et, H & $\mathbf{5 e}, 81$ & $\mathbf{6 e}, 48$ \\
6 & $i-$ Pr, H & $\mathbf{5 f}, 80$ & $\mathbf{6 f}, 44$ \\
7 & benzo & $\mathbf{5 g}, 91$ & $\mathbf{6 g}, 31$ \\
\hline
\end{tabular}

$\mathrm{a}_{\mathbf{4}} \mathbf{g}=$ 1-naphthylmagnesium bromide. group was displaced with a series of aryl Grignard reagents 4, yielding biaryloxazolines $\mathbf{5 a - f}$ (Scheme 1 and Table 1). Removal of the oxazoline by methylation, reduction and hydrolysis returned the aldehydes $\mathbf{6 a}-\mathbf{f}$.

\section{Screening for selectivity by NMR}

In order to investigate the ratios of diastereoisomers formed as these aldehydes condensed with the resolving agents, 6a was mixed with 1 equiv of either 7 or 8 in toluene- $d_{8}$ or benzene- $d_{6}$ in an NMR tube (Scheme 2). The temperature of the tube was raised stepwise from $\mathrm{rt}$ to $110{ }^{\circ} \mathrm{C}$ as indicated in Table 2, allowing $30 \mathrm{~min}$ at each temperature and monitoring the changing ratio of diastereoisomers by ${ }^{1} \mathrm{H}$ NMR. We assume that the condensations are diastereoselective at the new stereogenic centre, in accordance with literature precedent [15,25-27,34,35].

At temperatures below $70{ }^{\circ} \mathrm{C}$, mixtures of diastereoisomeric imidazolidines $\mathbf{9}$ and oxazolidines $\mathbf{1 0}$ were observed with rather poor and somewhat variable selectivity $(1: 1-1.5: 1)$. However, as the temperature rose above $80{ }^{\circ} \mathrm{C}$ in toluene- $d_{8}$, the ratio of diastereoisomers of imidazolidines 9 also rose as high as 5:1. The ratio of oxazolidines $\mathbf{1 0}$ reached 2:1 under the same conditions. The ratios in benzene- $d_{6}$ were somewhat lower in each case.
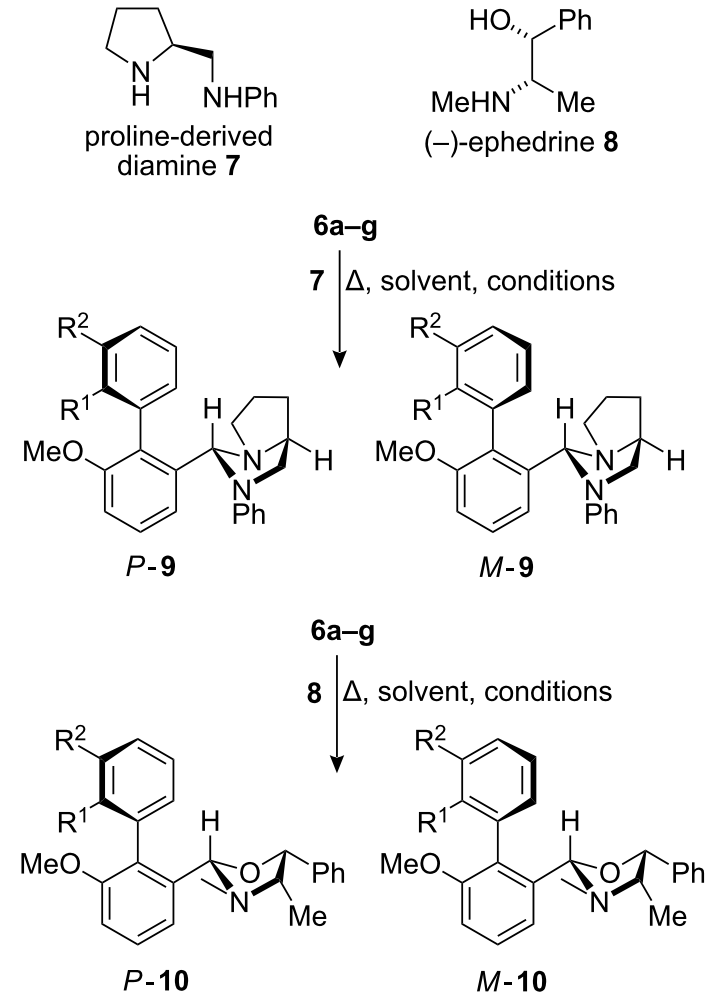

Scheme 2: Diastereoisomeric imidazolidines and oxazolidines from biaryl aldehydes. 
Table 2: Monitoring diastereoselectivity in the formation and/or interconversion of the diastereoisomers of imidazolidines $\mathbf{9 a}$ and oxazolidines $10 \mathrm{a}$

\begin{tabular}{lllll}
$\mathrm{T} /{ }^{\circ} \mathrm{C}$ & $\begin{array}{l}P-9 a: \\
M-9 a^{\mathrm{a}, \mathrm{b}}\end{array}$ & $\begin{array}{l}P-9 a: \\
M-9 a^{\mathrm{a}, \mathrm{c}}\end{array}$ & $\begin{array}{l}P-10 a: \\
M-10 a^{\mathrm{a}, \mathrm{b}}\end{array}$ & $\begin{array}{l}P-10 \mathrm{a}: \\
M-10 \mathbf{a}^{\mathrm{a}, \mathrm{c}}\end{array}$ \\
\hline 25 & $1: 1$ & $1: 1$ & - & - \\
40 & $1.5: 1$ & $1: 1$ & - & - \\
50 & $1.5: 1$ & $1: 1$ & $1.7: 1$ & $1: 1$ \\
60 & $1.5: 1$ & $1: 1$ & $1.5: 1$ & $1: 1$ \\
70 & $1.5: 1$ & - & $1.2: 1$ & $1.2: 1$ \\
80 & $1.8: 1$ & $1.6: 1$ & - & $1.2: 1$ \\
90 & $5: 1$ & $1.8: 1$ & - & $1: 1$ \\
100 & $5: 1$ & - & $2: 1$ & - \\
110 & $5: 1$ & - & $2: 1$ & - \\
\hline
\end{tabular}

aStereochemistry assigned by $\mathrm{X}$-ray crystallography: see below.

${ }^{\text {bSolvent }}=$ toluene- $d_{8}$. ${ }^{\text {cSolvent }}=$ benzene $-d_{6}$.

The increase in selectivity as the temperature rises is presumably the result of a thermodynamically controlled interconversion of the atropisomeric diastereoisomers of $\mathbf{9}$ and 10. It seems probable however that the varying selectivities at lower temperatures are the result of a complex interplay between the kinetic and thermodynamic factors.

\section{Preparative dynamic resolutions}

We decided to pursue this lead, and repeated the synthesis of 9 and $\mathbf{1 0}$ from $\mathbf{6 a}$ and also the other aldehydes $\mathbf{6 d}$ and $\mathbf{6 g}$. Equimolar quantities of $\mathbf{6}$ and either 7 or $\mathbf{8}$ were heated under a Dean-Stark condenser at reflux in either benzene, toluene or xylenes. The results are shown in Table 3.

Disappointingly, a ratio no greater than 3:1 was achieved, and this only when the reaction was conducted with 6a. Moreover, the selectivity at both lower and higher temperatures was diminished to $1: 1$, a feature which suggests that toluene has some special feature as a solvent irrespective of its boiling temperature. Nonetheless, when solutions of 9a and 10a were cooled to room temperature, the major diastereoisomer in each case crystallised from the solution in good yield. The X-ray crystal structures of these two compounds are shown in Figure 1 and Figure 2. $P$-9a was obtained in $81 \%$ yield and $P$-10a in $85 \%$ yield, despite the major diastereoisomer making up only $75 \%$ of the crude reaction mixture as judged by NMR. The fact that the yield is greater than the selectivity in solution must represent a crystallisation-induced transformation of one diastereoisomer into the other.

Other than scale, there is one significant difference between the reactions carried out in the NMR tubes and those in the DeanStark apparatus: in the NMR experiments, water was not removed during the reaction, and it seemed possible that the continued presence of water in the reaction mixture was contributing to the higher selectivities observed under some conditions in Table 2.

The preparative results were therefore repeated by heating equimolar amounts of the diamine 7 and the aldehydes 6 in toluene in a sealed tube at $110^{\circ} \mathrm{C}$ for $16 \mathrm{~h}$. Pleasingly, in three cases, the same 5:1 selectivity was observed as in the NMR experiments. Isolated yields of the three major diastereoisomers were moderate due o the challenging nature of the chromatographic purification.

In order to exploit the asymmetric transformation of $( \pm)-6$ into diastereoisomerically enriched $P \mathbf{- 9}$, a method for removal of the auxiliary was required. Previous experience $[25,27]$ had shown that hydrolysis and in situ reduction allows isolation of related compounds bearing hydroxymethyl groups, whose barriers to racemisation are somewhat higher than those of the corresponding aldehydes [37] obtained by hydrolysis alone.

Table 3: Preparative scale synthesis of imidazolidines 9 and oxazolidines 10 using (a) a Dean-Stark trap (DS) and (b) a sealed tube.

\begin{tabular}{|c|c|c|c|c|c|c|c|c|}
\hline $\begin{array}{l}\text { Starting } \\
\text { aldehyde }\end{array}$ & $\begin{array}{l}9^{a}, \mathrm{~b} \\
P: M\end{array}$ & $\begin{array}{l}9^{a}, \mathrm{c} \\
P: M\end{array}$ & $\begin{array}{l}9^{\mathrm{a}, \mathrm{d}} \\
P: M\end{array}$ & $\begin{array}{l}10^{\mathrm{a}, \mathrm{b}} \\
P: M\end{array}$ & $\begin{array}{l}10^{\mathrm{a}, \mathrm{c}} \\
P: M\end{array}$ & $\begin{array}{l}10^{\mathrm{a}, \mathrm{d}} \\
P: M\end{array}$ & $\begin{array}{l}9^{c}, \mathrm{e} \\
P: M\end{array}$ & $P-9 / \%{ }^{f}$ \\
\hline $6 a$ & $1: 1$ & $3: 1^{\mathrm{g}, \mathrm{h}}$ & $1: 1$ & $1: 1$ & $3: 1^{g, i}$ & $1: 1$ & $5: 19$ & 27 \\
\hline $6 b$ & - & - & - & - & - & - & $5: 1^{j}$ & 37 \\
\hline $6 c$ & - & - & - & - & - & - & $5: 1^{j}$ & 34 \\
\hline $6 d$ & $1: 1$ & $1: 1$ & $1: 1$ & $1: 1$ & $1: 1$ & $1: 1$ & $1: 1$ & 32 \\
\hline $6 e$ & - & - & - & - & - & - & $1: 1$ & 24 \\
\hline $6 f$ & - & - & - & - & - & - & $1: 1$ & 24 \\
\hline $6 g$ & $1: 1$ & $1: 1$ & $1: 1$ & $1: 1$ & $1: 1$ & $1: 1$ & $1: 1$ & 27 \\
\hline
\end{tabular}

acCarried out in a Dean Stark apparatus. bSolvent = benzene. ${ }^{\mathrm{c} S o l v e n t}=$ toluene. ${ }^{\mathrm{d}}$ Solvent $=x y l e n e .{ }^{\mathrm{e} C a r r i e d}$ out in a sealed tube. ${ }^{\mathrm{f}}$ Yield after chromatographical purification. 9Stereochemistry assigned by X-ray crystallography: see below. ${ }^{\mathrm{h}} 81 \%$ isolated on crystallisation. ${ }^{8} 85 \%$ isolated on crystallisation. jStereochemistry assigned by analogy with $10 a$. 


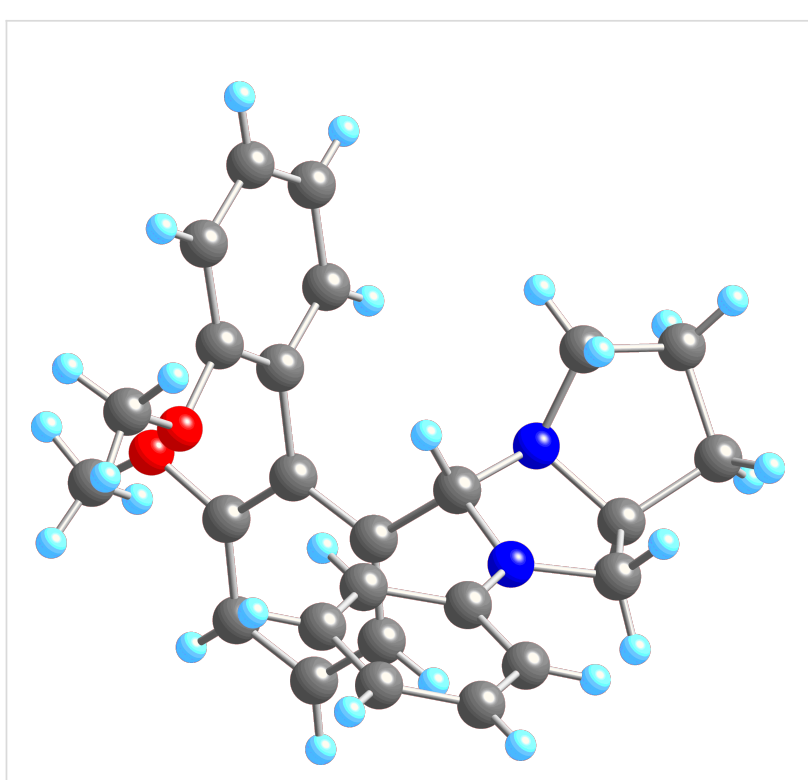

Figure 1: X-ray crystal structure of 9a. X-ray data has been deposited with the Cambridge Crystallographic Data Centre: deposition number 693530 .

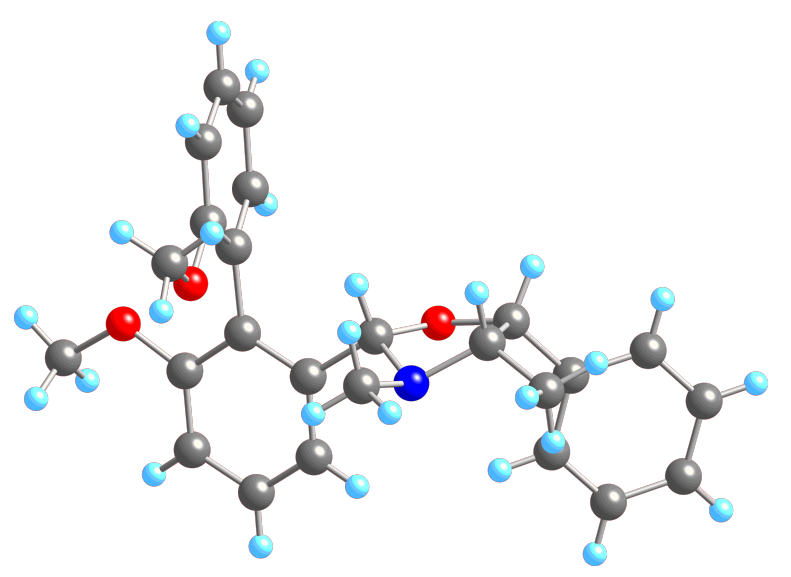

Figure 2: X-ray crystal structure of 10a. X-ray data has been deposited with the Cambridge Crystallographic Data Centre: deposition number 693529.

After trial reactions to establish optimal conditions, purified imidazolidines 9a were treated with aqueous $\mathrm{HCl}$ in $\mathrm{THF}$ at -5 ${ }^{\circ} \mathrm{C}$. After 35 min, a mixture of $\mathrm{NaBH}_{4}$ and $\mathrm{NaOMe}$ in methanol was added to neutralise the reaction mixture and to reduce the aldehyde to the atropisomeric alcohols 11 (Scheme 3). Table 4 shows the isolated yields of the essentially enantiomerically pure alcohols $P$-11 obtained. Enantiomeric ratios were determined by ${ }^{1} \mathrm{H}$ NMR in the presence of (+)-trifluoro-9-anthrylethanol, (+)-TFAE [38], comparing with authentic racemic samples of the alcohols made by simple reduction of $( \pm)-6$.

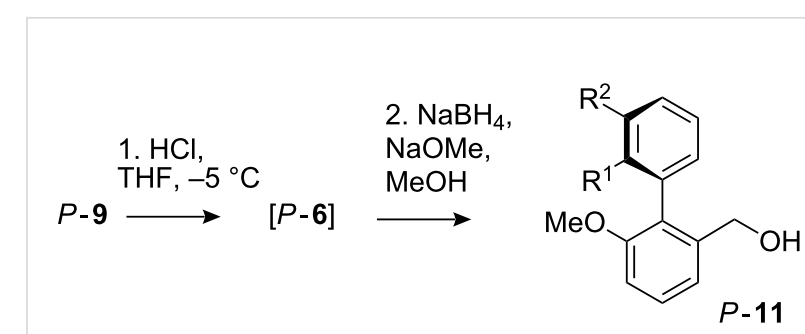

Scheme 3: Atropisomeric alcohols by hydrolysis and reduction.

Table 4: Isolation of imidazolidines and hydrolysis/reduction to atropisomeric alcohols 11 .

\begin{tabular}{llll} 
Imidazolidine & alcohol & yield & $\mathrm{Er}^{\mathrm{a}}$ \\
\hline$P-10 \mathbf{a}$ & $P-11 \mathrm{a}$ & 55 & $>98: 2$ \\
$P-10 \mathrm{c}$ & $P-11 \mathrm{c}$ & 28 & $>98: 2$ \\
$P-10 \mathrm{~d}$ & $P-11 \mathrm{~d}$ & 44 & $>98: 2$ \\
$P-10 \mathrm{e}$ & $P-11 \mathrm{e}$ & 43 & $>98: 2$ \\
\hline
\end{tabular}

aer determined by ${ }^{1} \mathrm{H}$ NMR in the presence of $(+)$-TFAE [38].

\section{Rationalisations of results}

The improved selectivity observed on use of a sealed tube suggests that the presence of water plays an important role in the determining the selectivity of the reaction (Scheme 4). The ratio of isomers of 9 observed in the NMR tube slowly improved on raising the temperature, and we propose that this observation is consistent with selectivity being under thermodynamic control, with $P \mathbf{- 9}$ being more stable than $M-\mathbf{9}$. However it seems that the attainment of the favourable equilibrium mixture of diastereoisomers requires both heat (to allow rotation about the hindered Ar-Ar bond in $\mathbf{6}$ or one of its derivatives) and water. Water would allow the imidazolidines 9 to hydrolyse back via iminiums 13 to hemiaminals 12 or the starting aldehydes 6 , which presumably have a lower barrier to bond rotation [37]. These observations are therefore consistent with the following rationalisation: in toluene, $P-6$ and $M-6$ may interconvert, and both react with diamine 7 to yield hemiaminals $\mathbf{1 2}$ and hence imidazolidines 9. Kinetic selectivity (such as that observed at lower temperatures, for example in benzene) is low. Moreover, $P-9$ and $M-9$ do not interconvert directly by bond rotation even in refluxing xylenes (we have confirmed this by heating $P-9$ a under these conditions). Nonetheless, the two diastereoisomers may attain thermodynamic equilibrium if an alternative mechanism for their interconversion presents itself, namely hydrolysis back to the aldehyde 6 (or maybe the hemiaminal 12). $P-9$ is more stable than $M-9$, and equilibration allows the ratio of $P: M-9$ to build up to about 5:1. High selectivity is disrupted if (a) the temperature is too low (presumably the case in reactions carried out in benzene: see Table 2) or 


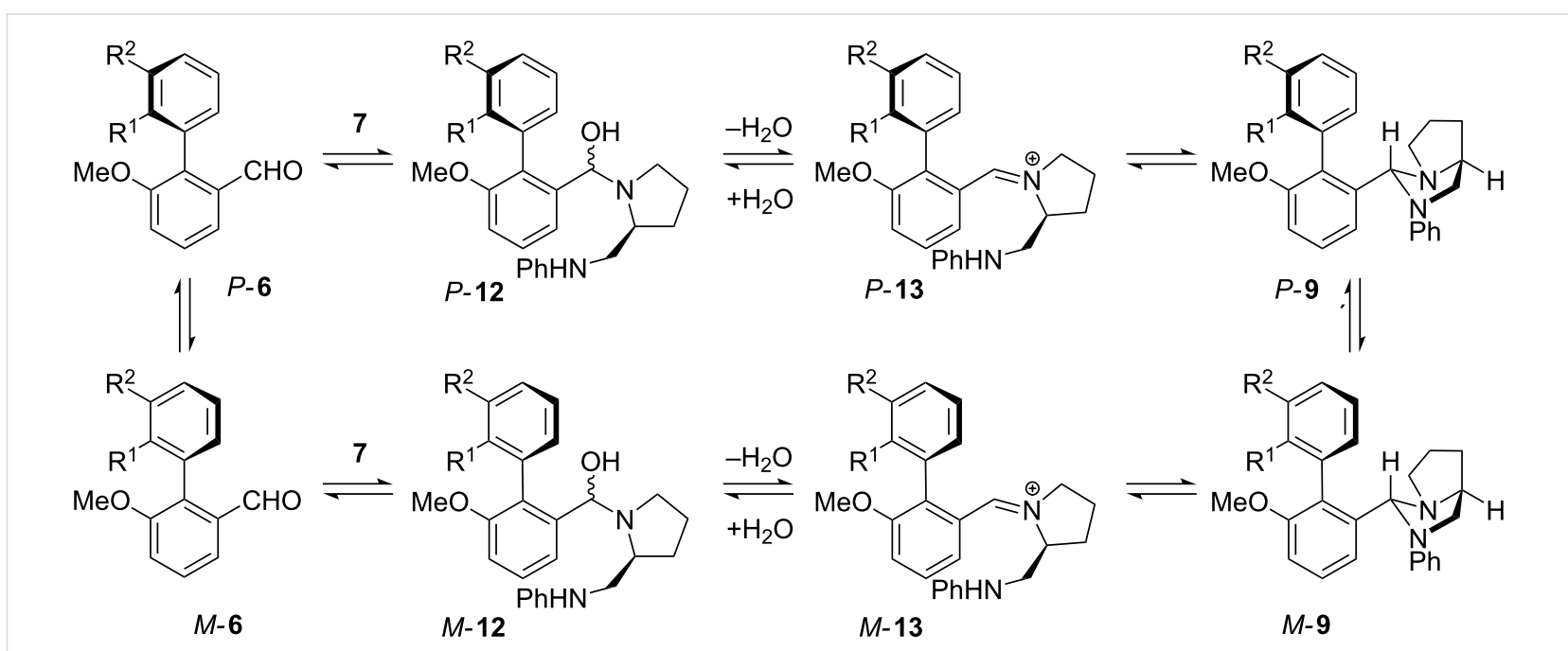

Scheme 4: Mechanistic rationalisation of the dynamic resolution in the formation of 9.

(b) water is driven out of the reaction either by high temperatures or by the use of a Dean-Stark apparatus. Toluene at $110^{\circ} \mathrm{C}$ provides the right balance of boiling point with ability to retain in solution a sufficient concentration of water to allow equilibration via the starting aldehydes.

\section{Conclusion}

Biaryl aldehydes may be resolved in a dynamic fashion by condensation with (-)-ephedrine, or, more effectively, a proline-derived diamine. The selectivity of the dynamic resolution depends significantly on conditions of the reaction, and is the result of a complex interplay of kinetic and thermodynamic effects. The best selectivities, of up to $5: 1$, were obtained on reaction of alkoxy-substituted biaryls with the diamine in a sealed tube, presumably because water plays a role in assisting interconversion of the atropisomeric products and allows thermodynamic equilibrium to be attained. The imidazolidine products may be hydrolysed and reduced to atropisomeric alcohols in moderate yield and with excellent enantioselectivity.

\section{Experimental}

For general experimental procedures, see Supporting Information File 1.

\section{General procedure for formation of imidazolidines 9}

The aldehyde $6(1 \mathrm{mmol})$ was heated at $110{ }^{\circ} \mathrm{C}$ with $(S)-(+)-2-$ (anilinomethyl)pyrrolidine [39] $(1 \mathrm{mmol})$ in toluene $(25 \mathrm{~mL})$ in a sealed tube overnight. The solvent was evaporated under reduced pressure, and the product was purified by flash chromatography to yield the corresponding imidazolidine.
(3R,7aS)-3-(6,2'-Dimethoxybiphenyl-2-yl)-2-phenylhexahydropyrrolo[1,2-c]imidazole (9a)

In this way, but on a $2 \mathrm{mmol}$ scale, aldehyde $\mathbf{6 a}$ gave, after purification by flash chromatography on alumina (eluent 5:1 v/v petroleum ether/EtOAc), the title compound 9a as a white solid (680 mg, 81\%). Mp 161-164 ${ }^{\circ} \mathrm{C} ;{ }^{1} \mathrm{H}$ NMR spectra indicated a mixture of conformers at a ratio of 5:1. Extensive purification by flash chromatography on alumina (eluent $5: 1 \mathrm{v} / \mathrm{v}$ petroleum ether/EtOAc) resulted in the separation of one diastereoisomer (227 mg, 33\% of initial yield). Mp $170-175^{\circ} \mathrm{C}$; $\mathrm{R}_{\mathrm{f}} 0.32(5: 1 \mathrm{v} /$ $\mathrm{v}$ petroleum ether/EtOAc ); IR $v_{\max }$ (thin film) (DCM) 3012, 2933, 1637, 1599, 1050, $1434 \mathrm{~cm}^{-1}$; ${ }^{1} \mathrm{H}$ NMR (300 MHz, $\left.\mathrm{CDCl}_{3}\right) \delta ; 7.44-7.38(1 \mathrm{H}, \mathrm{m}$, biaryl- $H), 7.38-7.33(1 \mathrm{H}, \mathrm{m}$, biaryl- $H), 7.28(1 \mathrm{H}, \mathrm{t}, J 8$, biaryl- $H), 7.19(2 \mathrm{H}, \mathrm{dt}, J 7$ and 1 , biaryl- $H), 7.12(1 \mathrm{H}, \mathrm{dt}, J 6$ and 1, biaryl- $H), 7.04(1 \mathrm{H}, \mathrm{d}, J 8$, Ph- $H), 6.96(1 \mathrm{H}, J 8, \mathrm{Ph}-H), 6.68(1 \mathrm{H}, \mathrm{t}, J 7, \mathrm{Ph}-H), 6.58(2 \mathrm{H}$, $\mathrm{d}, J 8, \mathrm{Ph}-H), 5.02(1 \mathrm{H}, \mathrm{s}, \mathrm{CHN}), 3.92\left(3 \mathrm{H}, \mathrm{s}, \mathrm{OCH}_{3}\right)$, 3.85-3.72 (1H, m, $\left.\mathrm{PhNCH}_{2} \mathrm{CH}\right), 3.78\left(3 \mathrm{H}, \mathrm{s}, \mathrm{OCH}_{3}\right), 3.17(1 \mathrm{H}$, t, J 9, $\left.\mathrm{PhNCH}_{2}\right), 2.55-2.46\left(1 \mathrm{H}, \mathrm{m}, \mathrm{PhNCH}_{2}\right), 2.28-2.17(1 \mathrm{H}$, $\left.\mathrm{m}, \mathrm{NCH}_{2}\right), 2.15-2.02\left(1 \mathrm{H}, \mathrm{m}, \mathrm{NCH}_{2}\right), 1.87-1.65(4 \mathrm{H}, \mathrm{m}$, $\left.\mathrm{NCH}_{2} \mathrm{CH}_{2} \mathrm{CH}_{2}\right) ;{ }^{13} \mathrm{C}$ NMR $\left(75 \mathrm{MHz}, \mathrm{CDCl}_{3}\right) \delta ; 157.5$

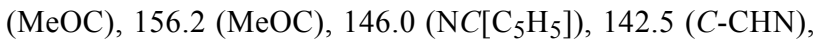
133.1, 128.8, 128.5, 128.4 (aromatics), 126.2, $125.2(\mathrm{Cq})$, $120.3,117.2,115.8,112.4,110.4,110.2$ (aromatics), $81.5^{+}$ $(\mathrm{CHN}), 60.3^{+}\left(\mathrm{NCHCH}_{2}\right), 56.0^{+}(\mathrm{OMe}), 55.2^{+}(\mathrm{OMe}), 53.2^{-}$ $\left(\mathrm{CH}_{2}\right), 53.2^{-}\left(\mathrm{CH}_{2}\right) ; \mathrm{m} / \mathrm{z}(\mathrm{CI}) 401(\mathrm{M}+1,100 \%)$. Mass measurement $400.2143, \mathrm{C}_{26} \mathrm{H}_{28} \mathrm{~N}_{2} \mathrm{O}_{2}$ requires 400.2150 . $[\alpha]_{\mathrm{D}}{ }^{25}=$ +213.2 ( $c=0.201$, ethanol).

Also obtained was a mixture of both diastereoisomers (453 mg, $67 \%$ of initial yield). 
In another experiment, the crude mixture was recrystallised from IPA to yield 9a as a crystalline solid (81\%).

\section{General procedure for formation of oxazolidines 10}

The aldehyde 6 ( $1 \mathrm{mmol}$ ) was heated to reflux with $(1 R, 2 S)-(-)-$ ephedrine $(1 \mathrm{mmol})$ in toluene $(25 \mathrm{~mL})$ for $24 \mathrm{~h}$. The solvent was evaporated under reduced pressure, and the product 10 was purified by flash chromatography to yield the corresponding oxazolidine.

\section{(2S,4S,5R)-2-(6,2'-Dimethoxybiphenyl-2-yl)-3,4-} dimethyl-5-phenyloxazolidine (10a)

Aldehyde 6a (608 mg, $2.51 \mathrm{mmol}$ ) gave, after flash chromatography on alumina (eluent $5: 1 \mathrm{v} / \mathrm{v}$ petroleum ether/EtOAc), the title compound 10a as a white solid $(731 \mathrm{mg}, 75 \%)$. Mp 131-135 ${ }^{\circ} \mathrm{C}$; ${ }^{1} \mathrm{H}$ NMR spectra indicated a mixture of conformers at a ratio of $3: 1$.

In another experiment, recrystallisation of the crude material from IPA gave $(P)-\mathbf{1 0 a}$ as a crystalline solid $(85 \%) . \mathrm{R}_{\mathrm{f}} 0.40(5: 1$ $\mathrm{v} / \mathrm{v}$ petroleum ether/EtOAc ); IR $v_{\max }$ (thin film) (DCM) 3124 , 2954, 1582, 1499, 1250, $801 \mathrm{~cm}^{-1}$; ${ }^{1} \mathrm{H}$ NMR (300 MHz, $\left.\mathrm{CDCl}_{3}\right) \delta ; 7.80-7.02(12 \mathrm{H}, \mathrm{m}, \mathrm{Ar} H), 5.05(1 \mathrm{H}, \mathrm{d}, J 8, \mathrm{PhCH})$, $4.40(1 \mathrm{H}, \mathrm{s}, \mathrm{NCHO}), 3.84\left(6 \mathrm{H}, \mathrm{s}, \mathrm{OCH}_{3}\right), 2.85(1 \mathrm{H}, \mathrm{qn}, J 7$, $\left.\mathrm{CH}_{3} \mathrm{CH}\right), 2.15\left(3 \mathrm{H}, \mathrm{s}, \mathrm{NCH}_{3}\right), 0.80\left(3 \mathrm{H}, \mathrm{d}, J 7, \mathrm{CHCH}_{3}\right)$; ${ }^{13} \mathrm{C} \mathrm{NMR}\left(75 \mathrm{MHz}, \mathrm{CDCl}_{3}\right.$ ): 164.8, 164.2, 139.3, 136.2, 129.8, $128.5,128.2,128.1,127.6,127.1,126.5,126.2,125.9,124.3$, 122.3, 122.1, 114.3, 113.9, 93.6, 82.1, 65.4, 57.2, 56.5, 37.6, 14.5; $\mathrm{m} / \mathrm{z}$ (CI) $390(\mathrm{M}+1,100 \%)$. Mass measurement 389.1985, $\mathrm{C}_{25} \mathrm{H}_{27} \mathrm{NO}_{3}$ requires 389.1991. Anal. Calcd for $\mathrm{C}_{25} \mathrm{H}_{27} \mathrm{NO}_{3}$ : C, 77.09, H, 6.99, N, 3.60; Found C, 76.79; H, 7.13; N, 3.66. $[\alpha]_{\mathrm{D}}{ }^{25}-134.9(c=0.512$, chloroform $)$.

\section{Supporting Information}

Procedures for the synthesis, and characterisation data, of the remaining compounds reported in this paper.

\section{Supporting Information File 1}

Full experimental data for all new compounds reported in the paper.

[http://www.beilstein-journals.org/bjoc/content/ supplementary/1860-5397-4-47-S1.doc]

\section{Acknowledgments}

We are grateful to GlaxoSmithKline and to the EPSRC for studentships (to $\mathrm{AB}$ and LWL).

\section{References}

1. McCarthy, M.; Guiry, P. J. Tetrahedron 2001, 57, 3809. doi:10.1016/S0040-4020(01)00087-4

2. Michaud, G.; Bulliard, M.; Ricard, L.; Genêt, J.-P.; Marinetti, A. Chem.-Eur. J. 2002, 8, 3327.

doi:10.1002/1521-3765(20020802)8:15<3327::AID-CHEM3327>3.0.C $\mathrm{O} ; 2-\mathrm{F}$

3. Noyori, R. Asymmetric Catalysis in Organic Synthesis; Wiley: New York, 1994.

4. Bringmann, G.; Walter, R.; Weirich, R. Angew. Chem., Int. Ed. Engl. 1990, 29, 977. doi:10.1002/anie.199009771

5. Bringmann, G.; Walter, R.; Weirich, R. Biaryls. In Stereoselective Synthesis; Helmchen, G.; Hoffmann, R. W.; Mulzer, J.; Schaumann, E., Eds.; Methods of Organic Chemistry (Houben-Weyl), Vol. E21a; Georg Thieme Verlag: Stuttgart, 1992; pp $567 \mathrm{ff}$.

6. Bringmann, G.; Hinrichs, J.; Pabst, T.; Henschel, P.; Peters, K.; Peters, E.-M. Synthesis 2001, 155. doi:10.1055/s-2001-9760

7. Wallace, T. W. Org. Biomol. Chem. 2006, 4, 3197. doi:10.1039/b608470m

8. Cammidge, A. N.; Crépy, K. V. L. Chem. Commun. 2000, 1723 doi:10.1039/b004513f

9. Yin, J.; Buchwald, S. L. J. Am. Chem. Soc. 2000, 122, 12051. doi:10.1021/ja005622z

10. Bringmann, G.; Breuning, M.; Tasler, S. Synthesis 1999, 525. doi:10.1055/s-1999-3435

11. Clayden, J. Chem. Commun. 2004, 127. doi:10.1039/b307976g

12. Ahmed, A.; Bragg, R. A.; Clayden, J.; Lai, L. W.; McCarthy, C.; Pink, J. H.; Westlund, N.; Yasin, S. A. Tetrahedron 1998, 54, 13277. doi:10.1016/S0040-4020(98)00814-X

13. Clayden, J.; McCarthy, C.; Cumming, J. G. Tetrahedron Lett. 2000, 41, 3279. doi:10.1016/S0040-4039(00)00397-X

14. Clayden, J.; Helliwell, M.; McCarthy, C.; Westlund, N. J. Chem. Soc., Perkin Trans. 1 2000, 3232. doi:10.1039/b004682p

15. Clayden, J.; Lai, L. W.; Helliwell, M. Tetrahedron: Asymmetry 2001, 12, 695. doi:10.1016/S0957-4166(01)00110-0

16. Clayden, J.; Mitjans, D.; Youssef, L. H. J. Am. Chem. Soc. 2002, 124 5266. doi:10.1021/ja017702o

17. Betson, M. S.; Clayden, J.; Worrall, C. P.; Peace, S. Angew. Chem., Int. Ed. 2006, 45, 5803. doi:10.1002/anie.200601866

18. Adler, T.; Bonjoch, J.; Clayden, J.; Font-Bardia, M.; Pickworth, M.; Solans, X.; Solé, D.; Vallverdú, L. Org. Biomol. Chem. 2005, 3, 3173. doi:10.1039/b507202f

19. Clayden, J.; Lemiègre, L.; Pickworth, M.; Jones, L. Org. Biomol. Chem. 2008, 6, 2908. doi:10.1039/b802673d

20. Clayden, J.; Turner, H.; Helliwell, M.; Moir, E. J. Org. Chem. 2008, 73, 4415. doi:10.1021/jo702706c

21. Caddick, S.; Jenkins, K. Chem. Soc. Rev. 1996, 25, 447. doi:10.1039/CS9962500447

22. Ward, R. S. Tetrahedron: Asymmetry 1995, 6, 1475. doi:10.1016/0957-4166(95)00179-S

23. Noyori, R.; Tokunaga, M.; Kitamura, M. Bull. Chem. Soc. Jpn. 1995, 68, 36. doi:10.1246/bcsj.68.36

24. Beak, P.; Anderson, D. R.; Curtis, M. D.; Laumer, J. M.; Pippel, D. J.; Weisenburger, G. A. Acc. Chem. Res. 2000, 33, 715. doi:10.1021/ar000077s

25. Clayden, J.; Lai, L. W. Angew. Chem., Int. Ed. 1999, 38, 2556. doi:10.1002/(SICI)1521-3773(19990903)38:17<2556::AID-ANIE2556 $>3.0 . \mathrm{CO} ; 2-\mathrm{Q}$

26. Clayden, J.; Lai, L. W. Tetrahedron Lett. 2001, 42, 3163. doi:10.1016/S0040-4039(01)00416-6 
27. Clayden, J.; Lai, L. W.; Helliwell, M. Tetrahedron 2004, 60, 4399. doi:10.1016/j.tet.2004.01.101

28. Clayden, J.; Johnson, P.; Pink, J. H.; Helliwell, M. J. Org. Chem. 2000, 65, 7033. doi:10.1021/jo0007074

29. Clayden, J.; Kubinski, P. M.; Sammiceli, F.; Helliwell, M.; Diorazio, L. Tetrahedron 2004, 60, 4387. doi:10.1016/j.tet.2004.01.099

30. Clayden, J.; Worrall, C. P.; Moran, W. J.; Helliwell, M. Angew. Chem., Int. Ed. 2008, 47, 3234. doi:10.1002/anie.200705660

31. Clayden, J.; Stimson, C. C.; Keenan, M. Synlett 2005, 1716. doi:10.1055/s-2005-871554

32. Betson, M. S.; Bracegirdle, A.; Clayden, J.; Helliwell, M.; Lund, A.; Pickworth, M.; Snape, T. J.; Worrall, C. P. Chem. Commun. 2007, 754. doi:10.1039/b614618j

33. Betson, M. S.; Clayden, J.; Helliwell, M.; Mitjans, D. Org. Biomol. Chem. 2005, 3, 3898. doi:10.1039/b511452g

34. Clayden, J.; Lund, A.; Vallverdú, L.; Helliwell, M. Nature (London) 2004, 431, 966. doi:10.1038/nature02933

35. Clayden, J.; Lund, A.; Youssef, L. H. Org. Lett. 2001, 3, 4133. doi:10.1021/ol0167457

36. Meyers, A. I.; Flanagan, M. E. Org. Synth. 1993, 71, 107.

37. Meyers, A. I.; Flisak, J. R.; Aitken, R. A. J. Am. Chem. Soc. 1987, 109, 5446. doi:10.1021/ja00252a022

38. Pirkle, W. H.; Sikkenga, D. L.; Pavlin, M. S. J. Org. Chem. 1977, 42, 384. doi:10.1021/jo00422a061

39. Asami, M.; Ohno, H.; Kobayashi, S.; Mukaiyama, T. Bull. Chem. Soc. Jpn. 1978, 51, 1869. doi:10.1246/bcsj.51.1869

\section{License and Terms}

This is an Open Access article under the terms of the Creative Commons Attribution License

(http://creativecommons.org/licenses/by/2.0), which permits unrestricted use, distribution, and reproduction in any medium, provided the original work is properly cited.

The license is subject to the Beilstein Journal of Organic Chemistry terms and conditions:

(http://www.beilstein-journals.org/bjoc)

The definitive version of this article is the electronic one which can be found at: doi:10.3762/bjoc. 4.47 